\title{
Sodium Disorders: Hyponatraemia
}

Authors: Dr. Noel Somasundaram, Prof. Chandrika Wijeyarathne, Dr. Henry Rajaratnam, Dr. Prasad Katulanda, Dr. Uditha Bulugahapitiya, Dr. Sajith Siyambalapitiya, Dr.Charles Antonypillai, Dr. Manilka Sumanathilake, Dr. Chaminda Garusinghe, Dr. Dimuthu Muthukuda, Dr. M. W. S. Niranjala, Dr. Muditha Weerakkody, Dr. Sivatharshya Pathmanathan, Dr. Sachith Abeyarathne, Dr. Shyaminda Kahandawa, Dr. Samanthi Cooray, Dr. Kavinga Gunawardena, Dr. Nayananjani Karunasena, Dr. W. S. T. Swarnasri, Dr. M. Aravinthan, Dr. D. C. Kottahachchi, Dr. N. A. S. Ariyawansa

Sri Lanka Journal of Diabetes, Endocrinology and Metabolism 2013; 3: 114-122

\section{Introduction}

Hyponatraemia is the most common electrolyte abnormality observed in hospitalized patients, and is associated with complications such as seizures, increased mortality and prolonged hospitalization. The risk of symptoms, complications and death increases with severity of hyponatraemia (1).

Table 1. Levels of severity of hyponatraemia

\begin{tabular}{lc}
\hline Severity & Serum sodium $(\mathbf{m m o l} / \mathbf{L})$ \\
\hline Mild & $130-134$ \\
Moderate & $120-129$ \\
Severe & $<120$
\end{tabular}

Table 2. Symptoms of hyponatraemia

The symptoms of hyponatraemia are primarily neurological, and worsen as sodium concentration drops (4). They include:

- Headache

- Nausea, loss of appetite, vomiting

- Malaise

- Lethargy

- Weakness

- Poor coordination

- Muscle cramps

- Somnolence

- Disorientation

- Personality change
Hyponatraemia is defined as a serum sodium concentration below $135 \mathrm{mmol} / \mathrm{l}(2)$.

Mild or slowly developing hyponatraemia is usually asymptomatic. In contrast, severe hyponatraemia, particularly rapid onset hyponatraemia is associated with substantial morbidity and can be life-threatening (3).

Table 3. Complications of severe and rapidly evolving hyponatraemia (5)

- Seizures

- Coma

- Permanent brain damage

- Respiratory arrest

- Brain-stem herniation

- Death

\section{Epidemiology}

- Hyponatraemia occurs in $15 \%$ of hospitalized patients. $67 \%$ of cases are hospital acquired $(6,7)$.

\section{Evaluation of hyponatraemia}

The Aims of evaluation are:

- To identify possible cause(s) and

- To decide the best treatment

This is achieved through clinical evaluation and relevant laboratory investigations.

Disclaimer: Clinical Practice Guidelines are developed to be of assistance to health care professionals by providing guidance and recommendations for particular areas of practice. The Guidelines should not be considered inclusive of all proper approaches or methods, or exclusive of others. The Guidelines cannot guarantee any specific outcome, nor do they establish a standard of care. The Guidelines are not intended to dictate the treatment of a particular patient. Treatment decisions must be made based on the independent judgment of health care providers and each patient's individual circumstances.

The Endocrine Society of Sri Lanka makes no warranty, express or implied, regarding the Guidelines and specifically excludes any warranties of merchantability and fitness for a particular use or purpose. The society shall not be liable for direct, indirect, special, incidental, or consequential damages related to the use of the information contained herein.

(c)Endocrine Society of Sri Lanka 


\section{Clinical evaluation}

- Assess the Severity: Conscious level and mental Status

- Assess the duration of hyponatraemia

- Assess Volume Status: (hypovolaemic/ euvolaemic/hypervolaemic)

o Look at mucous membranes, skin turgor, dependent edema, JVP, pulse, blood pressure, postural drop

o Check urine colour/concentration and volume

o Go through fluid balance chart (polyuria, negative vs. positive fluid balance)

o Assess Central Venous Pressure if feasible
- Go through the drug history carefully: identify any causative drugs such as diuretics, ACEI/ ARB, NSAIDs, anti-epileptics, chemotherapeutic agents etc.

- Look for underlying illness: Congestive cardiac failure, cirrhosis, renal failure, nephrotic syndrome, hypothyroidism

- Look for possible etiology: SIADH, CSW (Cerebral salt wasting), SAH (Sub arachnoid hemorrhage)

\section{Laboratory Investigations}

- Urine Spot Sodium with simultaneous Serum Sodium

- Urine Osmolality and Serum Osmolality (optional)

Figure 1. Evaluation of hyponatraemia $(8,9)$

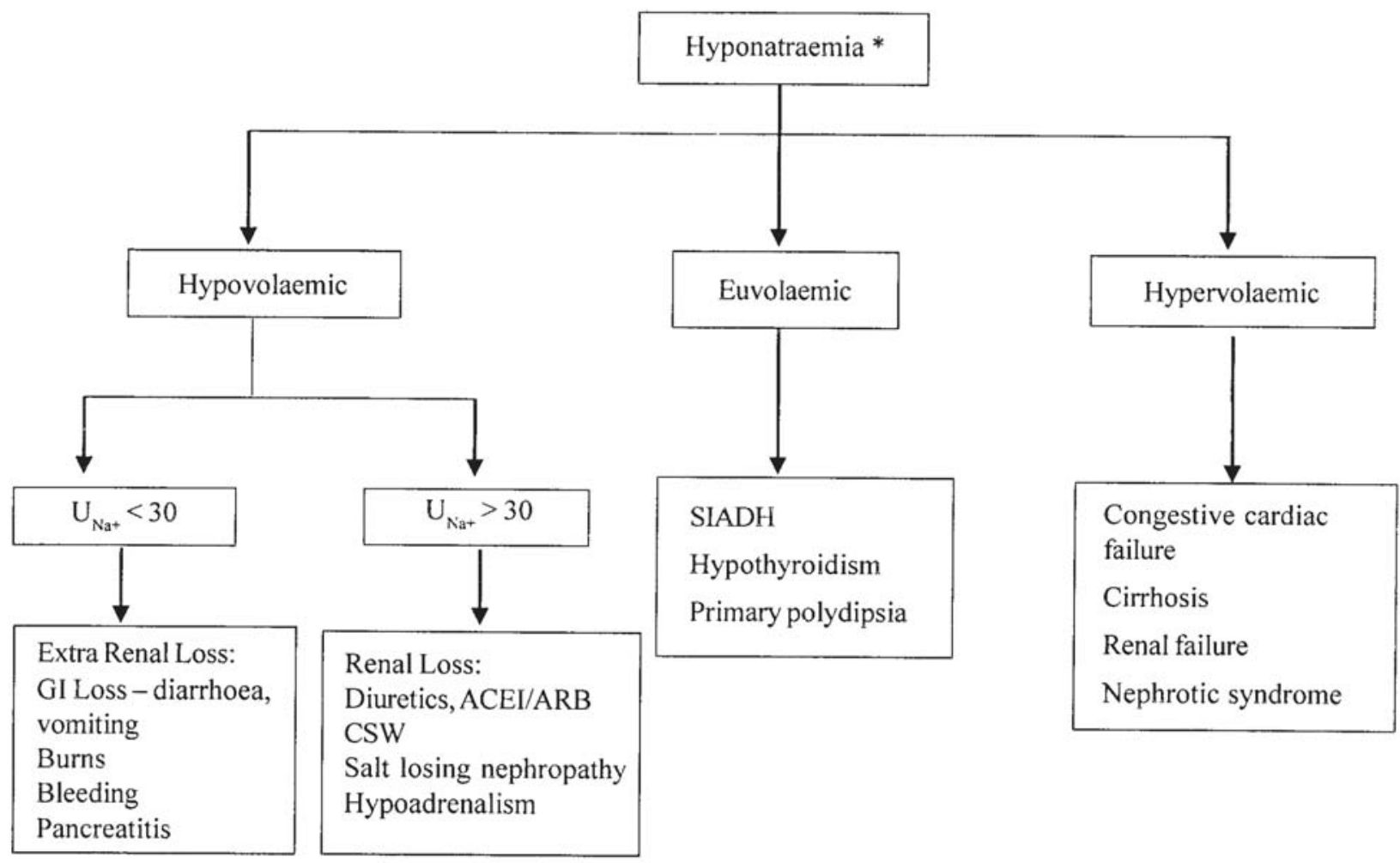

- Pseudohyponatraemia is suspected in the absence of clinical features or underlying pathology

- The serum $\mathrm{Na}+$ will be low but the measured osmolality will be normal or high. Causes of pseudohyponatraemia include: severe hyperglycaemia, severe hyperlipidaemia, hyperproteinaemia, and administration of mannitol

Patients may require other tests to exclude possible underlying aetiology of hyponatraemia depending on clinical suspicion.

E.g. Primary polydipsia, Hypothyroidism, Hypoadrenalism 


\section{Management of hyponatraemia}

\section{General Rules}

1. The presence or absence of symptoms and the duration of the hyponatraemia should guide the treatment strategy.

2. Extra caution should be taken in managing neurosurgical hyponatraemia as symptoms may be more prominent in patients with cerebral insults but may not reflect the hyponatraemia per se.

3. If an underlying cause can be identified, specific therapy is indicated.

E.g.: - Stopping diuretics

- Instituting appropriate hormone replacement therapy for glucocorticoid insufficiency and/or hypothyroidism

\section{Main Principles}

- Avoid overcorrection

- In chronic hyponatraemia serum sodium must be monitored closely and corrected no faster than

o $10-12 \mathrm{mmol} / \mathrm{L}$ in the first 24 hours

o $18 \mathrm{mmol} / \mathrm{L}$ in the first 48 hours

- In the presence of predisposing factors for central pontine myelinolysis correction rate should be even lower ( $\leq 8 \mathrm{mmol} / \mathrm{L}$ in $24 \mathrm{~h}$ period).

- Acute hyponatraemia (duration < 48 h) can be safely corrected more quickly than chronic hyponatraemia.

- In severe symptomatic patients (e.g., severe confusion, coma, seizures), hypertonic saline is indicated with the therapeutic target being improvement of symptoms or serum sodium $>120 \mathrm{mmol} / \mathrm{L}$.

\section{Central pontine myelinolysis (osmotic demyelination syndrome)}

Characterized by focal demyelination in the pons and extrapontine areas causing serious neurologic sequelae (10).

Risk factors for central pontine myelinolysis in the hyponatraemic patient are:

o Serum sodium of less than $120 \mathrm{mmol} / \mathrm{L}$ for more than 48 hours

o Aggressive IV fluid therapy with hypertonic saline solutions

o Development of hypernatraemia during treatment (overcorrection)

o Hypokalaemia

o Alcoholism and/or malnutrition

o Liver disease

\section{SIADH}

- Diagnostic Criteria (9)

o Serum osmolality $<275$ mOsm/kg with inappropriately high urinary osmolality $>100 \mathrm{mOsm} / \mathrm{kg}$

o Clinical euvolaemia

o Elevated urinary sodium excretion (Urine Spot Sodium $>40 \mathrm{mmol} / \mathrm{L}$ ) with normal salt and water intake

o Absence of other causes of euvolaemic hypoosmolality

- Once SIADH is diagnosed it is recommended to look for possible underlying aetiology e.g. drugs (anti-epileptics, anti-psychotics etc.), CNS and lung pathology, malignancy

\section{Management of hyponatraemia in SIADH}

- Cornerstone of SIADH treatment is fluid restriction

- Severe symptomatic SIADH can be treated with hypertonic saline

- SIADH may be treated with urea, diuretics, lithium, demeclocycline, vaptans and/or fluid restriction

\section{Management of hyponatraemia in SAH (8)}

- Hyponatraemia in SAH patients at risk of vasospasm should not be treated with fluid restriction

- Patients with severe symptoms or subarachnoid haemorrhage (SAH) at risk of vasospasm should receive hypertonic saline

- SAH patients should receive treatment even for a serum sodium level of 131 to $135 \mathrm{mmol} / \mathrm{L}$.

- Sodium should not be corrected by more than $10 \mathrm{mmol} / \mathrm{d}$

- Fludrocortisone may be considered in the treatment of hyponatraemia in SAH patients at risk of vasospasm

- Hydrocortisone may be used to prevent natriuresis in SAH patients

- CSW should be treated with replacement of sodium and intravenous fluids 
Figure 2. Management of hyponatraemia

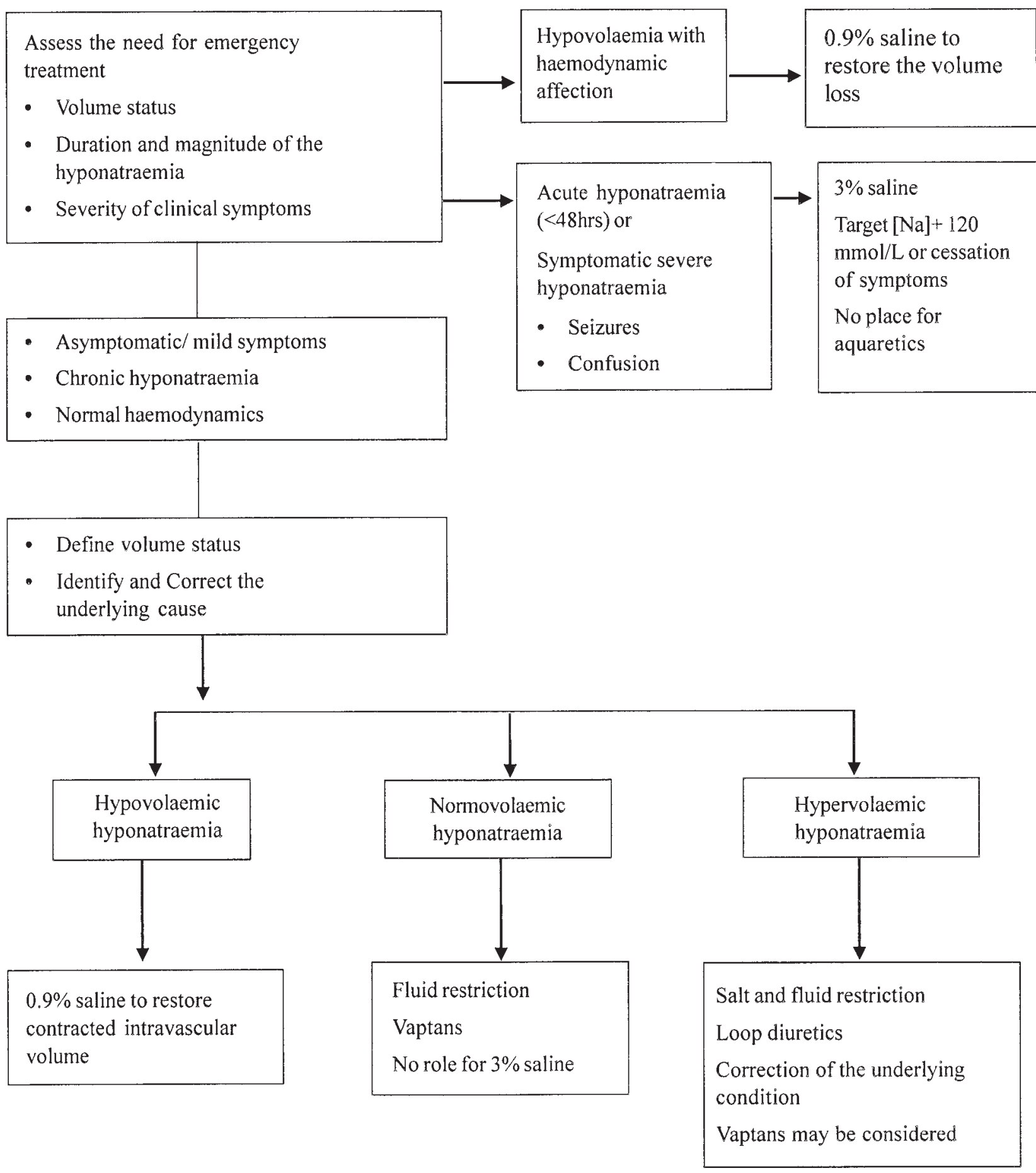

\section{Hypertonic saline correction}

- Multiply weight by desired correction rate and infuse as $\mathrm{ml} / \mathrm{h}$ of $3 \%$ saline.

- Target rate of correction is 1.5 to $2 \mathrm{mmol} / \mathrm{L}$ per hour with $3 \%$ saline for the first 3 to 4 hours, or more briefly, if symptoms improve or the sodium level exceeds $120 \mathrm{mmol} / \mathrm{L}$.

E.g. in a $70 \mathrm{~kg}$ patient in whom the desired correction rate is $0.5 \mathrm{mmol} / \mathrm{hour}$, the rate of infusion would be $(70 \times 0.5) 35 \mathrm{ml} /$ hour. 


\section{Principles of fluid restriction}

\section{General guidelines:}

- Restrict all intake that is consumed by drinking, not just water

- Aim for a fluid restriction that is $500 \mathrm{ml} / \mathrm{d}$ below the 24-hour urine output

- Do not restrict sodium unless indicated

\section{Predictors of failure of fluid restriction:}

- Urine sodium + potassium is greater than the serum sodium

- 24-hour urine output is less than $1,500 \mathrm{ml}$

- Increase in serum sodium after fluid restriction is less than $2 \mathrm{mmol} / \mathrm{L}$ in $24 \mathrm{~h}$

- High urine osmolality (>500 mOsm/kg H2O)

\section{How much to restrict / How much to give?}

$\mathrm{U} / \mathrm{P}$ ratio $=\frac{\mathrm{U}_{\mathrm{Na}}+\mathrm{U}_{\mathrm{K}}}{\mathrm{P}_{\mathrm{Na}}}$

$\mathrm{U}_{\mathrm{Na}}$ is the urinary $\left[\mathrm{Na}^{+}\right]$, UK is the urinary $\left[\mathrm{K}^{+}\right]$and $\mathrm{P}_{\mathrm{Na}}$ is the plasma/serum $\left[\mathrm{Na}^{+}\right]$. This simplified equation can be used to estimate free water loss in relation to the effective osmoles within the blood plasma (11).

Table 4. Recommended fluid consumption based on patient's U/P sodium ratio

\begin{tabular}{llll}
\hline Urine/plasma Na ${ }^{+}$ratio & $\begin{array}{l}\text { Insensible } \\
\text { water losses }\end{array}$ & $\begin{array}{l}\text { Expected net } \\
\text { water loss }\end{array}$ & $\begin{array}{l}\text { Recommended fluid } \\
\text { consumption }\end{array}$ \\
\hline$>1.0$ & $800 \mathrm{ml}$ & $800 \mathrm{ml}$ & $\begin{array}{l}\text { No oral fluids, use IV fluids if } \\
\text { indicated }\end{array}$ \\
$1.0-0.5$ & $800 \mathrm{ml}$ & $800-1300 \mathrm{ml}$ & Up to $500 \mathrm{ml}$ \\
$<0.5$ & $800 \mathrm{ml}$ & $1300-1500 \mathrm{ml}$ & Up to $1000 \mathrm{ml}$ \\
\hline
\end{tabular}

\section{References}

1. Thompson CJ , Crowley RK. Hyponatraemia. J R Coll Physicians Edinb 2009; 39:154-7.

2. Adrogue HJ, Madias NE. Hyponatraemia. $N$ Engl J Med 2000; 342: 1581.

3. Goh K. Management of Hyponatraemia. American Family Physician 2004; 69(10): 2387-94.

4. Renneboog B, Musch W, Vandemergel X, Manto MU, Decaux G. Mild chronic hyponatraemia is associated with falls, unsteadiness, and attention deficits. Am J Med 2006; 119: e1-8.

5. Bagshaw SM, Townsend DR, McDermid RC. Disorders of sodium and water balance in hospitalized patients. Can J Anesth 2009; 56: 151-67.

6. Eric E Simon, Seyed Mehrdad Hamrahian, et al. Hyponatraemia. Medscape.
7. $\quad$ Anderson RJ et al. Ann Intern Med 1985; 102: 164-8.

8. Rahman M, Freidman WA. Hyponatraemia in neurosurgical patients: Clinical guidelines development. Neurosurgery 2009; 65: 925-36.

9. Verbalis JG, Goldsmith SR, Greenberg A, Schrier RW, Sterns RH. Hyponatraemia treatment guidelines 2007: expert panel recommendations. Am J Med 2007; 120(11 Suppl 1): S1-21.

10. Murase T, Sugimura Y, Takefuji S, et al. Mechanisms and therapy of osmotic demyelination. Am J Med 2006; 119 (7 Suppl 1): S 69-73.

11. Furst H, Hallows KR, Post J, et al. The urine/plasma electrolyte ratio: a predictive guide to water restriction. $\mathrm{Am}$ J Med Sci 2000; 319: 240-44. 


\section{Sodium Disorders: Hypernatraemia}

\section{Introduction}

Hypernatraemia is defined as serum sodium concentration above $145 \mathrm{mmol} / \mathrm{L}$. Hypernatraemia invariably denotes hypertonic hyperosmolality and always leads to cellular dehydration.

\section{Epidemiology}

Hypernatraemia occurs in approximately $1 \%$ of hospitalized patients and incidence increases in debilitated elderly persons and in breastfed infants. Hypernatremia is associated with high morbidity and mortality and mortality rates are as high as 50\% (5).

\section{Etiology}

The causes of hypernatraemia are listed in table 1 however there may be more than one factor operational particularly in critically ill patients.

\section{Table 1. Causes of hypernatraemia}

\section{Pure water deficit}

- Inadequate intake or excessive insensible loss

- Renal loss

o Diabetes insipidus (central or nephrogenic)

\section{Water and sodium deficit}

- Extra renal loss

o Skin (burns, excessive sweating)

o Gastrointestinal Tract (viral gastroenteritis, osmotic diarrhea, vomiting)

- Renal loss

o Osmotic diuresis (hyperglycaemia, mannitol, high protein diet)

o Renal disease

o Post obstructive diuresis

o Resolving or polyuric phase of acute tubular necrosis

\section{Sodium gain}

- Hypertonic saline infusion

- Hypertonic feeding

\section{Transient}

- After seizure or vigorous activity
Table 2. Clinical features of hypernatraemia

\author{
Clinical features in adults \\ - Anorexia/nausea/vomiting \\ - Restlessness \\ - $\quad$ Twitching \\ - Hyperreflexia \\ - Ataxia \\ - $\quad$ Tremor \\ - Lethargy/irritability/stupor/ coma
}

$$
\begin{aligned}
& \text { Clinical features in children } \\
& \text { - } \text { Hyperpnoea } \\
& \text { - } \text { Muscle weakness } \\
& \text { - } \quad \text { Restlessness } \\
& \text { - } \text { Characteristic high-pitched cry } \\
& \text { - } \quad \text { Insomnia } \\
& \text { - } \quad \text { Lethargy } \\
& \text { - } \quad \text { Coma }
\end{aligned}
$$

- Adult patients generally have few symptoms until the serum sodium concentration exceeds 160 $\mathrm{mmol} / \mathrm{L}$.

- The level of consciousness is correlated with the severity of the hypernatraemia.

- Brain shrinkage induced by hypernatremia can result in vascular rupture, with cerebral bleeding, subarachnoid hemorrhage and permanent neurologic damage or death.

\section{Evaluation of hypernatraemia}

\section{History}

- Obvious water loss with no adequate replacement of water. e.g. Diarrhoea, vomiting, altered mental status

- Symptoms and possible causes of diabetes insipidus (DI). e.g. polyuria, polydipsia, cerebral pathology, drug history (lithium)

- Urine output: increased or decreased 


\section{Examination}

- Assessment of the volume status

- Features of volume depletion. e.g. postural drop, tachycardia

- Urine concentration:

o In dehydration there will be concentrated urine with reduced urine volume. The urine spot sodium is usually less than $10 \mathrm{mmol} / 1$

o In those with hypernatraemia a urine spot sodium more than $100 \mathrm{mmol} / 1$ usually indicates ingestion of salt/infusion of hypertonic saline solution

o Passing large volumes of dilute urine in the presence of hypernatraemia usually indicate diabetes insipidus

\section{Management of hypernatraemia}

Treatment of hypernatraemia requires a two pronged approach

- Correcting the prevailing hypertonicity.

- Addressing the underlying cause.

\section{Correcting the prevailing hypertonicity}

- The aim: Fall in the serum sodium concentration of $10 \mathrm{mmol} / 1$ per day

(Except those in whom the disorder has developed over a period of hours).

- The goal: Reduce the serum sodium concentration to $145 \mathrm{mmol} / \mathrm{l}$.

- The route: The preferred route for administering fluids is the oral route or a feeding tube; if neither is feasible, fluids should be given intravenously.

o Type of fluid:

o The more hypotonic the infusate, the lower the infusion rate required.

o Except in cases of frank circulatory compromise, $0.9 \%$ saline is unsuitable for managing hypernatraemia.

- Rate of infusion:

Change in serum $\mathrm{Na}^{+}$per litres of infusate $=\left(\right.$ infusate $\left.\mathrm{Na}^{+}\right)-\left(\right.$serum $\left.\mathrm{Na}^{+}\right)$ (total body water) +1

Usually total body water is calculated as $0.5 \times$ lean body weight
Table 3. Amount of sodium in various types of IV fluids

\section{Infusate}

$5 \%$ dextrose in water

$0.2 \% \mathrm{NaCl}$ in $5 \%$ dextrose

$0.45 \%$ sodium chloride

Ringer's lactate

$0.9 \%$ sodium chloride

\section{$\mathrm{Na}^{+}$(mmol per litre)}

\section{0}

154
E.g. If $5 \%$ dextrose is selected as the infusate to correct a sodium of $160 \mathrm{mmol} / \mathrm{l}$ in a $60 \mathrm{~kg}$ young male:

o Change in serum $\mathrm{Na}^{+}$per litre of infusate $=\frac{0-(160)}{(60 \times 0.5)+1}=-5.2$

o The aim is to reduce the sodium by $10 \mathrm{mmol} /$ 1 per day

o Therefore the amount of $5 \%$ dextrose required per day $=10 / 5.2=1.9$ litre per day or $80 \mathrm{ml} /$ hour

\section{Managing the underlying cause}

- Stopping the gastrointestinal fluid losses

- Treating the pyrexia

- Correcting the hyperglycaemia

- Treating hypercalcaemia and hypokalaemia

- Withholding lactulose and lithium

- Correcting the feeding preparation

- Apart from these causes patients with cranial or nephrogenic diabetes insipidus has to be managed with adequate $\mathrm{ADH}$ or ADH- analogs. 


\section{Cranial diabetes insipidus}

The treatment of choice for those with significant symptoms,

o DDAVP - (synthetic, long-acting vasopressin analogue): intranasal spray (10-40 mcg daily), parenteral injection (0.1-1.0 mcg daily) or oral (1001000 mcg daily), in divided doses.

o Optional - Vasopressin (5IU tid, bid, subcutaneously). Caution is required in patients with renal impairment and ischaemic heart disease.

o There is wide individual variation in the dose required to control symptoms.

o Dilutional hyponatraemia is the most serious potential adverse effect.

\section{Nephrogenic diabetes insipidus}

- Secondary/acquired cases are managed by removing the underlying cause.

- Ensure adequate hydration.

- There are various treatment options including:

o High dose DDAVP: may produce a response in partial nephrogenic diabetes insipidus, especially if the lesion is acquired.

o Diuretics

- Amiloride is beneficial in patients with reversible lithium nephrotoxicity.

- Thiazide diuretics: hydrochlorothiazide $25 \mathrm{mg} /$ day. o Non-steroidal anti-inflammatory drugs:

- Ibuprofen 200 mg/day. (caution in renal impairment)

o Low salt diets.

\section{References}

1. Adrogue HJ, Madias NE. Hypernatremia. $N$ Engl J Med 2000; 342(20): 1493-9.

2. Robertson G, et al. Relationship between fluid management, changes in serum sodium and outcome in hypernatraemia associated with gastroenteritis. J Paediatr Child Health 2007; 43(4): 291-6.

3. O'Connor KA, Cotter PE, Kingston M, Twomey C, O'Mahony D. The pattern of plasma sodium abnormalities in an acute elderly care ward: a cross-sectional study. Ir J Med Sci. 2006; 175(3): 28-31.

4. Robert SW. Mannual of nephrology. 7th ed. Lippincott and Wilkins, 2009: 22-37.

5. Turner HE, Wass JAH. Oxford Handbook of Endocrinology and Diabetes, 2nd ed. New York: Oxford University Press, 2009: 200-1.

6. Melmed S, Polonsky S. Kenneth, Larsen PR. Kronenberg HM.Williams Textbook of Endocrinology. 12th ed. Philadelphia: Saunders Elsevier. 2012: 296-7.

7. Al-Absi A, et al. A Clinical Approach to the Treatment of Chronic Hypernatremia. Am J Kidney Dis. 2012; 60(6): 1032-8.

8. Di Iorgi $\mathrm{N}$ et al. Diabetes Insipidus - Diagnosis and Management. Horm Res Paediatr 2012; 77: 69-84. 


\section{Annexure 1}

\section{Water deprivation test}

\section{Indications for water deprivation test}

- Suspected cranial/nephrogenic DI

- To rule out primary polydipsia

\section{Water deprivation test}

- Patient voids at the beginning of test and starting weight is recorded

- Nothing allowed by mouth

- Sample is taken for serum $\mathrm{Na}$

- $\quad$ Each voided urine is measured and corresponding urine osmolality is measured

- Weigh the patient hourly and document

- When patient has lost 3\% of body weight/ 2 consecutive urine osmolality differ no more than $10 \%$ blood for serum $\mathrm{Na}$ and osmolality is drawn.
- Patient is given $2 \mu \mathrm{g}$ of desmopressin iv/im

- Urine output and osmolality measured hourly for another 2 hours

\section{Interpretation}

- In normal individuals, when plasma osmolality rises [>295 mosm $/ \mathrm{kg}$ ] vasopressin [ADH] secretion is stimulated and urinary concentration is increased; usually $>600 \mathrm{mosm} / \mathrm{kg}$. There is no further rise in urine osmolality when exogenous $\mathrm{ADH}$ is given as endogenous ADH effect is maximum.

- Cranial DI - rise in urine osmolality $>50 \%$ after desmopressin

- Nephrogenic DI - rise in urine osmolality $<10 \%$

- Intermediate values in partial cranial/nephrogenic DI, osmotic diuresis

Table. Interpretation of urine osmolality [mosm/kg]

\begin{tabular}{lcc}
\hline Diagnosis & After fluid deprivation & After desmopressin \\
Cranial DI & $<300$ & $>800$ \\
Nephrogenic DI & $<300$ & $<300$ \\
Primary polydipsia & $>800$ & $>800$ \\
Partial DI/polydipsia & $300-800$ & $<800$ \\
\hline
\end{tabular}

